\title{
Essay on Playfulness and Play in Children's Art Class: A Reflection Based on Winnicott
}

\author{
Alain Savoie \\ Faculty of Education, Université de Sherbrooke, Sherbrooke, Canada \\ Email: alain.savoie@usherbrooke.ca
}

How to cite this paper: Savoie, A. (2019) Essay on Playfulness and Play in Children's Art Class: A Reflection Based on Winnicott. Creative Education, 10, 297-307. https://doi.org/10.4236/ce.2019.102024

Received: January 10, 2019

Accepted: February 17, 2019

Published: February 20, 2019

Copyright (C) 2019 by author(s) and Scientific Research Publishing Inc. This work is licensed under the Creative Commons Attribution International License (CC BY 4.0).

http://creativecommons.org/licenses/by/4.0/

\begin{abstract}
From a survey of literature, this article presents some reflections about the value of play and playfulness as, respectively, an activity and a creative attitude of mind to be fostered in art education in children. Indeed, at the heart of any artistic creative impulse sits a playful attitude of the artist towards reality - a feature that has been highlighted by the psychoanalyst Winnicott. Following his line of thought, we propose that the art teacher must place the learner in a position of being able to play with her/him, in order to overlap their two areas of playing and establish a learning space. Playfulness and play tend to be confused with impulsive and disruptive behaviours and generally more tolerated at home then school. We claim that artistic activities in school should always be play-based and take place in a playful environment because art and creation emerge from and grow in and as play.
\end{abstract}

\section{Keywords}

Playfulness, Play, Creativity, Winnicott, Child Art Class, Child Development

\section{Concerning Playfulness}

From a survey of literature, we present some reflections about the value of play and playfulness as, respectively, an activity and a creative attitude of mind to be fostered in art education in children. Indeed, we argue that the heart of any artistic creative impulse shows a playful attitude towards reality. Furthermore, we propose that the art teacher must place the learner in a position of being able to play with her/him, in order to overlap their two areas of playing and establish a learning space, a concept that has been highlighted in psychotherapy by the psychoanalyst Winnicott, but that we consider applicable in education, as shall be explained later on. 
Playfulness is an attitude of mind while play should be considered as an act (Akhtar, 2011). Playfulness affects the approach taken to any activity and may be viewed on a continuum of being more or less playful (Howard \& McInnes, 2013). Akhtar describes playfulness "as a character trait and/or interactional pattern comprised of light-heartedness, spontaneity, pleasure experienced in the context of mutuality, and a transient suspension of the reality-unreality boundary" (Akhtar, 2011: p. 82). In particular, researches have closely linked playfulness and play with creativity and art-making (Winnicott, 2005; Lieberman, 1977; Wing, 1995; Howard \& McInnes, 2013; Bateson \& Martin, 2013; Sicart, 2014; Szekely, 2015). Furthermore, playfulness brings optimism and joie de vivre, and drives creativity in both children and adults (Bateson \& Martin, 2013; Lieberman, 1977; Piaget, 1976; Rogers, 1959; Torrance, 1962). In fact, playfulness is one of the differentiating traits of the most creative boys and girls in elementary classrooms. The more playful children are often the more creative (Torrance, 1962; Lieberman, 1977). The hypothesis is that either playfulness boosts creativity or a predisposition to be creative to enhance playfulness. In any event, there is evidently a causal link between play, playfulness and creativity. According to Bateson \& Martin (2013):

[...] new forms of behaviour and new modes of thought frequently derive from play, and especially from playful play. Such activity is a driver of creativity and, less directly, of innovation [...] (p. 4).

However, playfulness is not necessarily a token of virtue and doesn't always guarantee healthy behaviours. In fact, some perversions of play could happen (Akhtar, 2011). Cruelty and greed may be very playfull and foster a perverse kind of creativity. Even depressing moods and states of crisis may trigger artists' imagination and creativity by sharpening their sensitivity. This is not something young children can deal with, though; they rather need positive moods in order to feel secure and playfully play and create. It is reasonnable to say that depressing moods in children kill playfulness. Having said that, other negative feelings like envy or vengeance can generate a thrill, a kind of possibly very imaginative and perverse playfulness, even in children.

We hypothesise that a level of playfulness or some reserves of it are always necessary for creative action-in other words, for the adult to make the most of her/his depressing feelings and create something starting from the exacerbated sensitivity that a somber mood could instill. Even though playfulness is attached to positive moods most of the time, certain types of playfulness can be pathological. According to Akhtar (2011), three types of individuals with behaviours involving playfulness seem to exist, and not all reflect a healthy mental condition. Among all playfull adult individuals, those reflecting a healthy mental condition would have the ability to put their playfulness aside when the social situation requires it. Conversely, adult individuals who cannot stop their playfull behaviours, whatever the situation, would reflect a psychopathology. The same applies to individuals who are depressive, obsessional, paranoid or schizoid and consequently 
not able of being playfull. In other words, those who cannot stop being playfull should be distinguished from those who feel playful most of the time and, when the context so requires, are able to either reduce or put playfulness aside. The latter behaviour is rather the sign of mentally and physically healthy persons, feeling good about themselves, and fully enjoying life with a sense of joie de vivre. So much said, in children, this notion of mental heath shows a more nuanced picture related to the attitude of mind called playfulness and the ability to put it aside. By definition and depending on their age, children are, to varying degrees, immature and irresponsible, meaning that their self-control is in development. It follows that their ability to put their natural playfulness aside when required shall adjust as they grow up with some help from educators. In children, this ability cannot be considered as a relevant indicator of mental health, but the impossibility for a child to be playfull would be.

\section{Play}

Piaget (1976) asserts that during the first months of our life, everything is play-except for eating and expressing emotions such as fear and anger-in other words when basic needs have been satisfied and the child is free from stress. "The origins of playfulness can be traced to the earliest period of infancy, when social referencing and pleasure in the discovery of new relational and conceptual patterns make their first appearance" (Akhtar, 2011: p. 72). Play and the first artistic babblings of the child are intimately linked. Children are playfully scribbling by themselves before practicing any other play. Howard \& McInnes (2013) point out that children enjoy mark-making from a very early age and, often, their first attempts involve the smearing of food over a highchair surface or table top. They appear to delight in both the texture they experience and the growing understanding that their actions are causing the patterns and marks to appear. Vygotsky (2013) proposes that early marks are indicative of children's first attempts at symbolic communication.

Playfulness is the mood of the small child if he fills secure, comfortable, free to live a meaningful life, and if the basic biological needs are fulfilled. Playfulness underlies pure life enjoyment and a creative drive in the sense that the infant is fully available and open to experiencing the world, establishing new patterns and combining actions and thoughts in new ways. A child may easily reach high levels or intensities of playfulness while an adult strives to be playfull (Bateson \& Martin, 2013).

The British psychoanalyst D. W. Winnicott (2005) developed in the seventies a very influential theory of play that still deserves attention. He hypothesised a basic and existential notion of play that underlies the very process of human reasoning and creativity. Just like Piaget (1976), Winnicott sees playing happening at the very beginning of the newborn baby's life. At first, the infant has no conception of an outside world. He makes no distinction between the ego and the nonego (Zérillo, 2012). His only experience "is that when he is hungry, he can eat, or when he feels cold, he becomes warm. Milk and blankets come as 
if out of nowhere in response to his feeling a need" (Adès, 2017). This is a fusional baby-mother relationship. The baby has no external framework yet. Milner (2010) would say that the infant's "experience is as yet a wholeness in which subject and object are still united". He is "[...] not born knowing the difference between thoughts and things, not born knowing the difference between subjective and objective, it is a knowledge only slowly acquired" (p. 32). The infant literally thinks that he creates the world spontaneously as he wishes. Winnicott calls it "illusion", that is to say a fusional relationship with the mother. Later on, the baby dissociates himself from his mother and perceives an outside world. Then he begins to play at creating. There is now more than her/his own imagination. There "is a world out there to be found and be frustrated by" (Ibid.). The pleasure principle hits the frustrating reality principle. The infant feels that he both finds and creates the objects around him. The infant is in what Winnicott (Ibid.) called an "intermediate area of experience". It is a space for playing. The playing child is absorbed in concentration, a near-withdrawal state, a transitional state between the child's inner and outer reality. In this play area, the child gathers phenomena from external reality in the service of his inner reality. "The area of playing is not inner psychic reality. It is outside the individual, but it is not the outside world" (Winnicott, 2005: p. 69). Playing happens between the child's inner subjective world and the external objective reality, where the imagination can shape the external world. It means that playing is not strictly imaginative nor in an out-of-control external world. As Milner (2010) puts it: "The substance of experience is what we bring to what we see, without our own contribution we see nothing" (p. 33). This leads us to hypothesise that because they don't yet have a strong mental construct, which generally interferes with and is detrimental to the aesthetic perception of the world, children quite naturally and easily let things be and enjoy the world through a perception that could be qualified as aesthetic (Savoie, 2017). Most artists wish to dive within themselves to bring back this aesthetic innocence and creative playfulness where thoughts and things merge. There is also this ideal of visual perception of the reality embodied in the "fresh therefore sensitive eye" of the young child. The debate and speculations around the sensitivity of a child's visual perception are ongoing, although some research in developmental psychology by Piaget and followers had shed a little light on this question. The same fascination with children's perception of reality existed at the beginning of the $20^{\text {th }}$ century among modern painters in their quest for the origins of art (Pernoud, 2015). For example, like many painters of his time, Kandinsky had a high regard for the perception of the young child. A child's perception was an ideal for the artist, because it was still free of the limits proclaimed by words, common sense and the practical world, still able "to see things in themselves". Kandinsky, Matisse, Klee, Picasso and others considered infancy as the golden age of visual perception, a sensitivity that would become blunted over time if not preserved and sustained (Savoie, 2017; Pernoud, 2015; Ehrenzweig, 1995). That is why art teachers should exploit and preserve their pupils' precious child's sensitivity. 
Because the accommodation to reality is infinite, the intermediate area is a necessity not only of childhood. According to Winnicott (2005), this intermediate area of experience remains, with its creative process continuing throughout life and expanding into a new common space, the cultural space of the arts, religion, philosophy, imaginary life, sciences, etc. In other words, Winnicott perceives human culture as what he calls a "potential space". Culture would be the collective continuity of an individual creative process initiated in early childhood. Tension between a person's interiority and exteriority is part of the human condition. This tension opens a "potential space" allowing human culture to emerge. This space becomes a kind of rest area, relieving humans from their existential tragic condition (Zérillo, 2012). It is an area of discovery and creation in which the entire human culture-meaning the inherited human tradition in all fields, from arts to mathematics-originates and expands. As Praglin (2006) puts it:

The artist creates and recreates unconscious processes, and presents these in a manner which resonate with our shared sense of symbols. By articulating these shared symbols, the artist invites us into this intermediate area of experiencing (p. 5).

In other words, Winnicott's intermediate area of experience and potential space are play areas where art is made; hence the inseparability of the arts from play, as both arise from the same mold. Winnicott (2005: p. 54) argues that it "is in playing and only in playing that the individual child or adult is able to be creative [...]". In sum, art and creation emerge and grow in and as play (Huizinga, 1971).

How should play be defined? The word play is associated with a variety of activities but must be characterized by the capacity to extract oneself from current reality and to be engaged in a free-thinking attitude (Pieron, 2003). Huizinga (1971) defines play as a free act that is felt as fictional, situated outside everyday life, thus a meta-situation, and able to totally engross the player (Metra, 2006). Free of any material interest or utility, play takes place in specifically circumscribed time and space. It unfolds in an orderly manner, following established rules and fostering group relation in life. Vygotsky (2013) writes about play rules:

To imagine that a child can behave in an imaginary situation without rules, i.e. as he behaves in a real situation, is simply impossible. If the child is playing the role of a mother, then she has rules of maternal behavior. The role the child plays, and her relationship to the object if the object has changed its meaning, will always stem from the rules, i.e. the imaginary situation will always contain rules.

Mystery and strangeness sometimes purposely surround play to contrast it from the everyday world. In the same line of thought, Eberle (2014) claims that play is "purposeless, voluntary, outside the ordinary, fun, and focused by rules" (p. 215). He proposes six basic elements characterising the field of play: 
"anticipation, surprise, pleasure, understanding, strength, and poise" (p. 222). In that sense, Bateson \& Martin (2013) propose five requirements for a play act: intrinsic motivation, protected context, novel combinations, repetition, and sensitivity to conditions. One can realize that those definitions of play could perfectly apply to art-making, because art belongs to the paradigm of play, although the artistic kind of play is quite serious in adulthood. Indeed, adults play more seriously than children. The playful attitude or disposition, in both children and adults, is one of freedom where creative forces can have free play.

John Dewey (2010) considered playfulness as more important than play because one may play without being really playful. At the core of a meaningful and fulfilled life lies our capacity, in most situations, to maintain a state of mind called playfulness, while at the same time taking the world seriously. The internal and affective qualities of play become the most important. Enthusiasm, motivation and willingness to engage (Sicart, 2014), which characterise playfulness, are more essential than the act of play itself. When this positive mood is present in the play act, one enjoys what Lieberman (1977) calls a playful-play, to be distinguished from play. It is not because a child is engaged in what looks like a play act that he actually feels playful (Howard \& McInnes, 2013) and is in a creative mood. Children benefit from playfulness much more than from the play act itself, because when they feel playful, kids can try out new ideas, safely resolve conflicts and anxieties, and show some creativity. This means that teachers should focus much more on playfulness than on the observable act of play itself (Ibid.).

\section{Playfulness, Play and Art Making}

For a long time, among professional artists, "play and playfulness have often been a strategy to either produce works of art or challenge the art world establishment" (Sicart, 2014: p. 61). There is a long tradition of using play as an element of artistic practice, with Dada and Surrealism being good examples. The history of modern and contemporary art abounds in playful creative approaches (Kaprow, 2003; Sicart, 2014). In fact, at the heart itself of any artistic creative impulse sits a playful attitude of the artist towards reality-a feature that has been highlighted by the psychoanalyst D. W. Winnicott (2005), a great figure of the child development worthwhile to revisit, as we shall discuss later. A playful state of mind generates creativity "in the sense of generating novel actions or ideas, particularly by recombining existing actions, ideas or thoughts in new ways or applying them in new situations" (Bateson \& Martin, 2013: p. 55). We hypothesise that this generated creativity in some way surfs the intrinsic uncertainty which underlies the human condition. The creative individual deals with uncertainty and play with it in full and playfull acceptance.

At the beginning of the $20^{\text {th }}$ century, the French psychologist Henri Delacroix ${ }^{1}$ (1927) noted that basic link between art and play. He claimed, among other

${ }^{1}$ Henri Delacroix (1873-1937). 
things, that both provide an escape from the constraints of reality and daily life. Years earlier, the celebrated German poet and philosopher Schiller (2012) associated aesthetics with playfulness in a series of letters published in 1794 called "On the aesthetic education of man". According to Schiller, where there is aesthetic freedom, there is always a play instinct. Furthermore, he claimed that the playful attitude or playful spirit of an individual puts him in a state of unrestrained freedom and fulfilment. The individual thereby feels less serious and somber about the tragedy of the human condition and therefore less paralyzed and inhibited. Playfulness stimulates the celebration of life. A free, harmonious and strong human nature reveals itself in play. What's more, the individual can only play when he is fully human (Ibid.). Hence, playfulness implies well-being and must not be confused with restless agitation. Actually, play "is usually the first activity to disappear if an individual is stressed, anxious, hungry or ill" (Bateson \& Martin, 2013: p. 19). In the same line of thought, Sicart (2014) claims that "to play is to be in the world. Playing is a form of understanding what surrounds us and who we are, and a way of engaging with others. Play is a mode of being human (p. 1)".

\section{Playfulness, Play, Art and School}

According to psychoanalyst Winnicott (2005), the "intermediate area of experience" is the overlap of two areas of playing, originally between the inner child and the external reality. Somehow, these areas can extend between the patient and the therapist. Winnicott (Ibid.) argues that:

Psychotherapy takes place in the overlap of two areas of playing, that of the patient and that of the therapist. Psychoanalysis has to do with two people playing together. The corollary of this is that where playing is not possible then the work of the therapist is directed towards bringing the patient from a state of not being able to play into a state of being able to play [...]. Psychoanalysis has been developed as a highly specialized form of playing [...]. The reason why playing is so essential is that it is in playing that the patient is being creative (p. 51-56-72).

We hypothesise that the same principle of "intermediate area of experience" and play areas could apply in the art education context and even in education in general. We propose that all methods of play practices are fully applicable to art education in children, provided that the education is permeated with playfulness. Following Winnicott's line of thought, but without considering therapeutic preoccupations and settings, we hypothesise that art education may be dealing with two persons playing together: the teacher and the pupil, both absorbed in the concentration instilled by the playful-play of the art activity. Learning itself might take place in the overlap of two areas of playing, that is to say Winnicott's intermediate area of experience between the teacher and the learner. Winnicott (2005) states that playing leads into relationships and is a basic form of life implying trust. When the child is playing, he splits himself in 
two and puts himself in a "meta-posture" (Metra, 2006). For Vygotsky (2013), it is as though the child would be a head taller than himself. While making art, children take the plunge to illustrate their experiences of the world with the seriousness of any child at play. They gather what little knowledge of the world they have and the few perceptual motor processes they possess. In addition, they gather some mental representations and representations of space they possess, as well as their little vocabulary of graphic forms, in order to symbolize visual data (Baldy, 2010). "Probably they can do this because the plunge is less of a plunge to them, since they live so much of their lives, through play, in a state where dream and external reality are fused" (Milner, 2010: p. 108). Play creates the child's zone of proximal development. While playing, the child always puts her/himself above her/his average age, above her/his daily behaviour, which is the best position for learning. When the learner is unable or refuses to play and to allow the intermediate area of experience to unfold, art learning may become pointless and possibly out of his/her reach, the learner remaining in an insensitive and aesthetically blind mood. It follows that the art teacher must bring the learner in a position of being able to play with her/him, in order to overlap their two areas of playing and set a learning space that opens a privileged, aesthetically oriented communication channel.

At school, art is often and traditionally presented through techniques and methods, possibly keeping children's playfulness low, over-controlled, even turned off. Teachers often perceive serious art-making separate from play. Research on children show that for them to be properly induced to play, they must be under a minimum of oversight, have different choices and enjoy freedom of action. These indicators can then orient the teacher in planning visual arts activities. Playfulness in no way subtracts from the seriousness of an activity; furthermore, with the anxiety level kept very low, playfulness helps to de-dramatize ticklish situations. Szekely (2015) asserts that "Play releases enormous tension and pent up emotions that easily build up in a highly regulated school environment" (p. 13).

For proof of this, one merely has to observe children playing to see the pleasure co-existing with their seriousness and concentration. This innate playfulness creates a secure and attentive state for the child's creative intelligence to have free rein. To that end, teachers should have a clear understanding of what play is in order to be comfortable with allowing children choice and control in their play (Howard \& McInnes, 2013). Playfulness and play tend to be confused with impulsive and disruptive behaviours (Lieberman, 1977). Of course, art education in children should foster a playful-play approach that is still based on art rules and principles. As said before, playfulness may be viewed on a continuum of being more or less playful (Howard \& McInnes, 2013). When playfulness is not pathological (Akhtar, 2011), the individuals retain the ability to put their playfulness aside when the context and purpose so require. A hyperexcited playful state might not be conducive to creativity if uncontrolled 
and disruptive. In that sense, a moderate tone is preferable. A playful attitude implies respecting the context and the purposes involved; in other words, being able to put playfulness aside or at least lessen its level, as the context or purpose requires.

In art, in contrast to the other school curriculum subjects, there are no ready-made solutions for how children should observe, feel, think or interpret something; in fact, such is the nature of playfulness (Howard \& McInnis, 2013). In art, however, the unique pedagogical significance of this playfulness derives from the extreme liberty it affords. For children thus come to feel more and more in control, accompanied and respected in the exercise of their creative freedom, their playful mind being both attentive and focused. Students will learn self-confidence and perseverance during their exploration and aesthetic experience. In short, a playful mind is an incubator for freedom of action. Playing typically is characterized by confidence and caring, which in turn, according to Winnicott (2005), open the way to a state of creative concentration. Children's art should be dealt with seriously, but it should also be a structured play in which everything is done to encourage the perseverance and exploration that are inherent to the creative process. Children are naturally prone to do what they have always done instinctively since infancy, i.e. play. Therefore, in an art class they play at being an artist and at creating. Besides gaining visual arts-related knowledge and skills, children learn also how to have fun with difficulties, deal with frustrations, and handle failure, and they enjoy doing so, relieved of decisive risks, once they listen, follow instructions and control their emotions (Howard \& McInnis, 2013). A playful classroom environment together with the de-dramatized learning situations will even incite the student to take risks and accept others' judgment with equanimity; this in turn will almost certainly have a positive effect on all aspects of children's education as they progress to adulthood.

\section{Conclusion}

According to the poet Schiller, where there is aesthetic freedom there is always a play instinct. The reverse might also be true, in the sense that playfulness might bring creativity and aesthetic freedom. At the core of a meaningful and fulfilled life lies our capacity, in most situations, to maintain a disposition of mind called playfulness while at the same time taking the world seriously. Play is so much an inherent part of us that it "is usually the first activity to disappear if an individual is stressed, anxious, hungry or ill (Bateson \& Martin, 2013: p. 19)”. This might be an indicator of the basic mode of being embodied in playful-play.

Playfulness is the mood of the small child if he fills secure, comfortable, and free to live a meaningful life, and if the basic biological needs are fulfilled. When playfulness is not pathological (Akhtar, 2011), that is when individuals retain the ability to put their playfulness aside as the context and purpose requires, playfulness underlies pure life enjoyment and the creative drives; the infant is 
thus fully available and open to experience the world, establish new patterns and combine actions and thoughts in new ways.

It follows that the practice of artistic activities in elementary school falls within the paradigm of children's play and therefore requires a playful attitude on the part of both the art teacher and the child. In the sense raised by Winnicott (2005) in a psychoanalysis setting, but transposed to art education, we propose that the art teacher must place the learner in a position of being able to play with her/him, in order to overlap their two areas of playing and establish an art learning space, a communication channel loaded with aesthetic sensitivity.

We claim that artistic activities in school should always be play-based and take place in a playful environment because, as Huizinga (1971) pointed out, art and creation emerge and grow as play.

\section{Conflicts of Interest}

The author declares no conflicts of interest regarding the publication of this paper.

\section{References}

Adès, R. (2017). Why Britain's Greatest Psychoanalyst, Donald Winnicott, Loved Doodles: Prizing Playfulness, Creativity and Spontaneity, Winnicott Developed the Squiggle Game to Communicate with Children. The Spectator.

https://www.spectator.co.uk/2017/05/why-britains-greatest-psychoanalyst-donald-win nicott-loved-doodles/

Akhtar, S. (2011). Normal and Pathological Playfulness. In M. C. Akhtar (Ed.), Play and Playfulness: Developmental, Cultural, and Clinical Aspects (pp. 69-84). Lanham, MA: Rowman and Littlefield.

Baldy, R. (2010). Dessine-Moi un bonhomme: Dessins d'enfants et développement cognitif. Paris: Éditions in Press.

Bateson, P., \& Martin, P. (2013). Play, Playfulness, Creativity and Innovation (Kindle Book Version). New-York, NY: Cambridge University Press.

https://doi.org/10.1017/CBO9781139057691

Delacroix, H. (1927). Psychologie de l’art: Essai sur l'activité artistique. Paris: Librairie Félix Alcan.

Dewey, J. (2010). How We Think. Createspace Independent Pub (Kindle Book Version). Createspace Independent Pub.

Eberle, S. G. (2014). The Elements of Play: Toward a Philosophy and a Definition of Play. Journal of Play, 6, 214-233.

Ehrenzweig, A. (1995). The Hidden Order of Art. Berkeley, CA: University of California Press.

Howard, J., \& McInnis, K. (2013). The Essence of Play: A Practice Companion for Professionals Working with Children and Young People (Kindle Book Version). New-York, NY: Routledge/Taylor and Francis. https://doi.org/10.4324/9780203075104

Huizinga, J. (1971). Homo Ludens: A Study of the Play-Element in Culture. Boston: Beacon Press.

Kaprow, A. (2003). Essays on the Blurring of Art and Life. Berkeley: University of California Press. 
Lieberman, J. N. (1977). Playfulness: Its Relationship to Imagination and Creativity. New-York: Academic Press.

Metra, M. (2006). Approches théoriques du jeu. IUMF Lyon. http://www2.ac-lyon.fr/etab/ien/ain/bourg2/IMG/pdf/Approches_theoriques_du_jeu.pdf

Milner, M. (2010). On Not Being Able to Paint (Kindle Book Version). London: Taylor and Francis. https://doi.org/10.4324/9780203833650

Pernoud, E. (2015). L'invention du dessin d'enfant en France, à l'aube des avant-gardes. Paris: Éditions Hanzan.

Piaget, J. (1976). La formation du symbole chez l'enfant: Imitation, jeu et rêve, image et représentation. Paris: Delachaux et Niestlé, Éditeurs. (Original Work Published 1945)

Pieron, H. (2003). Vocabulaire de la psychologie. Paris: PUF.

Praglin, L. (2006). The Nature of the In-Between in D.W. Winnicott's Concept of Transitional Space and in Martin Buber's das Zwischenmenschliche. Universitas, 2, $1-9$.

Rogers, C. R. (1959). Toward a Theory of Creativity. In H. H. Anderson (Ed.), Creativity and Its Cultivation (pp. 69-82). New York: Harper \& Brothers.

Savoie, A. (2017). Aesthetic Experience and Creativity in Arts Education: Ehrenzweig and the Primal Syncretistic Perception of the Child. Cambridge Journal of Education, 47, 53-66. https://doi.org/10.1080/0305764X.2015.1102864

Schiller, F. (2012). Lettres sur l'éducation esthétique de l'homme (E-Reader Version). Chicoutimi: Les classiques des sciences sociales. (Original Work Published 1796) http://classiques.uqac.ca/

Sicart, M. (2014). Play Matters. Kindle Book Edition, Cambridge, MA: The MIT Press.

Szekely, G. (2015). Play and Creativity in Art Teaching. New York, NY: Routledge. https://doi.org/10.4324/9780203072202

Torrance, E. P. (1962). Guiding Creative Talent. Englewood Cliffs, NJ: Prentice-Hall. https://doi.org/10.1037/13134-000

Vygotsky, L. (2013). Play and Its Role in Mental Development of the Child. Kindle Book Version, Psychology Classics Book I. (Original Work Published 1933) http://www.amazon.com/

Wing, L. (1995). Play Is Not the Work of the Child: Young Children's Perceptions of Work and Play. Early Childhood Research Quarterly, 10, 223-247. http://www.sciencedirect.com.ezproxy.usherbrooke.ca/science/journal/08852006/10/2 https://doi.org/10.1016/0885-2006(95)90005-5

Winnicott, D. W. (2005). Playing and Reality. London: Routledge. (Original Work Published 1971)

Zérillo, S. (2012). De l'illusion à la culture ou le regard de Winnicott sur la créativité. In Y. Fumat, \& Y. Monjot (Eds.), Petite enfance: Représentations et pratiques-Varia (pp. 1-15). Éducation et socialisation. Les Cahiers du CERFEE, No. 32. https://edso.revues.org/324?lang=en 